\title{
PEMBUATAN KOMPOSIT DARI LIMBAH PLASTIK POLYETHYLENE TEREPHTHALATE (PET) BERBASIS SERAT ALAM DAUN PANDAN LAUT (Pandanus tectorius)
}

\author{
MAKE A COMPOSITE FROM POLYETHYLENE TEREPHTHALATE \\ (PET) PLASTIC WASTE BASED ON SEA PANDAN LEAVES \\ (Pandanus tectorius)
}

\author{
Nuryati*, R.Rizki Amalia, Nina Hairiyah \\ ${ }^{1}$ Program Studi Agroindustri, Politeknik Negeri Tanah Laut \\ Jl. A.Yani, Km.6, Desa Panggung, kec. Pelaihari, Kab. Tanah Laut, Kalimantan Selatan 70815. Indonesia. \\ *Email korespondensi: nuryati@ politala.ac.id
}

Diterima 16-09-2020, diperbaiki 02-11-2020, disetujui 13-11-2020

\begin{abstract}
Composite is a material that is formed from a combination of two or more forming materials through an inhomogeneous mixing consisting of two parts, namely the matrix as a composite binder or protector and the filler as a composite filler. Pandan sea leaf (Pandanus tectorius) is one alternative natural material that can be used as a filler in making composites because it has a high cellulose content and has strong fiber properties. The purpose of this research was to describe the process of making composites with natural fiber fillers and characteristics of composites produced. Making composites through 4 steps, namely making sea pandanus leaf powder, making cellulose fraction, making polyethylene terephthalate (PET) plastic waste matrix, and making composite. Based on the results of the composite characterization research includes water content from $2.46 \%$ to $3.51 \%$, density from $0.49 \mathrm{~g} / \mathrm{cm}^{3}$ to $0.52 \mathrm{~g} / \mathrm{cm}^{3}$, porosity from $10.02 \%$ to $24.06 \%$, and absorption water that is $24.88 \%$ to $46.51 \%$. The type of MPA 1 (30\% filler cellulose sea pandanus leaves: $70 \%$ polyethylene terephthalate pellet matrix) had a moisture content that complies with SNI 01-4449-2006 that is $2.46 \%$, the corresponding density value SNI 03-2105-2006 is $0.52 \mathrm{~g} / \mathrm{cm}^{3}$, the porosity value that is in line with SNI 03-2105-2006 is 10.02\%, and the absorption according to JIS A5905-2003 standard is $24.88 \%$.
\end{abstract}

Keywords: Composite, cellulose, natural fiber, pandan sea leaves, polyethylene terephthalate

\begin{abstract}
ABSTRAK
Komposit merupakan material yang terbentuk dari kombinasi antara dua atau lebih material pembentuknya melalui pencampuran yang tidak homogen yang terdiri dari dua bagian yaitu matriks sebagai pengikat atau pelindung komposit dan filler sebagai pengisi komposit. Daun pandan laut (pandanus tectorius) merupakan salah satu alternatif bahan alam yang dapat digunakan sebagai filler dalam pembuatan komposit karena memiliki kandungan selulosa yang tinggi dan memiliki sifat serat yang kuat. Tujuan dari penelitian ini adalah mendiskripsikan proses pembuatan komposit dengan bahan pengisi serat alam serta melakukan karakterisasi komposit yang dihasilkan. Pembuatan komposit melalui 4 tahapan yaitu pembuatan serbuk daun pandan laut, pembuatan fraksi selulosa, pembuatan matriks limbah plastik polyethylene terephthalate (PET), dan pembuatan komposit. Berdasarkan hasil penelitian karakterisasi komposit meliputi kadar air yaitu 2,46\% sampai 3,51\%, densitas yaitu $0,49 \mathrm{~g} / \mathrm{cm}^{3}$ sampai $0,52 \mathrm{~g} / \mathrm{cm}^{3}$, porositas yaitu $10,02 \%$ sampai $24,06 \%$, dan daya serap
\end{abstract}


air yaitu 24,88\% sampai 46,51\%. Penentuan karakterisasi komposit terbaik yang diperoleh yaitu jenis KPL 1 (30\% filler selulosa daun pandan laut : 70\% matriks pellet polyethylene terephthalate) karena memiliki kadar air yang telah sesuai SNI 01-4449-2006 yaitu 2,46\%, nilai densitas yang telah sesuai SNI 03-2105-2006 yaitu $0,52 \mathrm{~g} / \mathrm{cm}^{3}$, nilai porositas yang telah sesuai SNI 03-2105-2006 yaitu $10,02 \%$, serta daya serap yang sesuai standar JIS A5905-2003 yaitu 24,88\%.

Kata Kunci: Daun pandan laut, komposit, polyethylene terephthalate, selulosa, serat alam

\section{PENDAHULUAN}

Perkembangan teknologi saat ini menuntut untuk dihasilkannya produk yang ramah lingkungan, biaya yang lebih ekonomis dan menggunakan bahan baku dari sumber daya alam yang dapat diperbaharui dalam aktivitas produksinya, salah satu contohnya yaitu industri komposit polimer (Hairiyah, et al., 2017). Komposit merupakan suatu material yang dibuat dengan penggabungan dua macam bahan yang mempunyai sifat berbeda menjadi satu material baru dengan sifat yang berbeda pula (Widiartha, et al., 2012) dan terdiri dari dua bagian yaitu matriks sebagai pengikat atau pelindung komposit dan filler sebagai pengisi komposit (Nopriantina dan Astuti, 2013).

Kalimantan Selatan merupakan wilayah yang memiliki panjang garis pantai mencapai $1.306,32 \mathrm{~km}$ serta memiliki kawasan mangrove seluas 106.967 ha yang meliputi wilayah pesisir pada 5 kabupaten yaitu Banjar, Tanah Laut, Tanah Bumbu, Kotabaru, dan Barito Kuala (Dewi dan Sofia, 2020). Mangrove terdiri dari mangrove sejati (true mangrove) dan asosiasi mangrove/mangrove pendamping (mangrove associates). Salah satu contoh tanaman mangrove pendamping yaitu tanaman pandan laut (pandanus tectorius). Daun pandan laut memiliki kandungan selulosa yang tinggi yaitu berkisar antara 83-88\% dan kandungan lignin berkisar antara $18-22 \%$. Selulosa mempunyai fungsi untuk memberikan kekuatan tarik pada suatu sel, sehingga semakin tinggi kadar selulosa maka kelenturan juga semakin tinggi (Gusmailina, 2010).

Daun pandan laut dapat menjadi alternatif serat alam sebagai bahan pengisi pada pembuatan komposit polimer. Menurut Zulkifli, et al., (2018), bahwa penggunaan serat alam memiliki keunggulan dibandingkan serat sintetis yaitu bersifat renewable, bisa didaur ulang (recyclable), aman bagi lingkungan dan kesehatan, memiliki sifat mekanis lebih baik, tidak menyebabkan abrasi pada alat, harganya lebih murah, dan densitas yang lebih rendah. Penelitian yang mengarah terhadap pengembangan komposit terus dilakukan, terutama pengembangan komposit berpenguat serat alam seperti purun tikus (Hairiyah, et al., 2017), serat daun nanas (Sriwita, 2014), hybrid serat sisal (Widiartha, et al., 2012), dan daun pandan alas (Taufik dan Astuti, 2014).

Pengembangan komposit tidak hanya pada bahan pengisi (filler) tetapi juga pada bagian matriksnya. Salah satunya dengan pemanfaatan polimer plastik sebagai matriks dalam pembuatan komposit, salah satunya plastik polyethylene terephthalate. Polyethylene terephthalate (PET) merupakan polyster termoplastik yang diproduksi secara komersial melalui produk kondensasi yang dikarakterisasi dengan banyaknya ikatan ester yang didistribusikan sepanjang rantai utama polimer (Armidion dan Rahayu, 2018). Plastik PET memiliki kekuatan tarik dan kekuatan yang sangat baik, begitu juga dengan ketahanan kimia, clarity, processability, kemampuan warna dan stabilitas termalnya (Okatama, 2016).

Penggunaan selulosa murni sebagai bahan pengisi serta pemanfaatan limbah polyethylene terephthalate sebagai matriks dalam pembuatan komposit merupakan salah satu cara modifikasi polimer sintetik untuk memperoleh komposit yang memiliki sifat fisik dan mekanik yang baik. Berdasarkan hal tersebut dapat disimpulkan 
bahwa daun pandan laut dapat dimanfaatkan sebagai bahan pengisi (filler) dan polyethylene terephthalate sebagai matriks dalam pembuatan komposit. Tujuan dari penelitian ini adalah mendiskripsikan proses pembuatan komposit dengan bahan pengisi serat alam serta menentukan karakteristik dari komposit yang dihasilkan.

Karakterisasi komposit dilakukan melalui beberapa pengujian yaitu kadar air, densitas, porositas, dan daya serap air. Kadar air merupakan sejumlah air yang terkandung di dalam suatu produk atau bahan. Kadar air merupakan karakteristik yang sangat mempengaruhi bahan seperti tekstur produk sehingga akan terjadi perubahan pada produk yang dihasilkan, selain kerusakan mikrobiologis, kadar air yang tinggi juga dapat mempengaruhi sifatsifat fisik seperti kekerasan dan kekeringan (Hairiyah, et al., 2017). Massa jenis (densitas) adalah pengukuran massa setiap satuan volume benda. Semakin tinggi massa jenis suatu benda, maka semakin besar pula massa setiap volumenya (Saputra, et al., 2017).

Porositas adalah perbandingan volume rongga-rongga pori terhadap volume total seluruh suatu bahan. Porositas dapat didefinisikan sebagai perbandingan antara jumlah volume ruang kosong (rongga pori) yang dimiliki oleh zat padat terhadap jumlah dari volume zat padat itu sendiri. Sedangkan daya serap air merupakan sifat fisis papan komposit yang menunjukkan sifat kemampuan papan untuk menyerap air selama perendaman di dalam air. Uji daya serap air dimaksudkan untuk mengetahui batas kemampuan komposit dalam menyerap air sampai batas maksimal (Izaak, et al., 2013). Penentuan karakteristik komposit bertujuan untuk mengetahui formulasi terbaik dalam pembuatan komposit sehingga dapat dihasilkan komposit terbaik yang dapat dilakukan pengembangan lebih lanjut.

\section{METODE PENELITIAN}

\begin{abstract}
Alat
Alat-alat yang digunakan dalam penelitian ini adalah gelas ukur, gelas beaker, cawan petri, neraca analitik, oven listrik, pipet ukur, blender, alat pirolisis, saringan, hot plate, serta alat cetak alumunium ukuran $4,5 \times 4,5 \times 1 \mathrm{~cm}$.
\end{abstract}

\section{Bahan}

Bahan-bahan yang digunakan dalam penelitian adalah daun pandan laut, polimer polyethylene terephthalate, maleic anhydride, tepung tapioka, aquadest, $\mathrm{NaOH} 15 \%$ dan $\mathrm{NaOCl} 1 \%$.

\section{Prosedur Penelitian}

Rancangan penelitian dalam penelitian ini adalah membuatn komposit dengan perbedaan komposisi matrix pellet polyethylene terephthalate dan filler daun pandan laut. Pengamatan karakteristik mekanik yang dilakukan meliputi perubahan sampel yang terjadi selama proses pengolahan, pengujian kadar air, pengujian densitas matrix pellet polyethylene terephthalate dan filler daun pandan laut, dan penentuan komposit terbaik. Berdasarkan hasil pengujian yang dilakukan akan diketahui karakteristik komposit terbaik dari kombinasi bahan baku yang digunakan untuk pembuatan pellet komposit.

Pengamatan karakteristik komposit yang dilakukan meliputi perubahan sampel yang terjadi selama proses pengolahan, perhitungan rendemen dan densitas matriks polyethylene terephthalate dan filler daun pandan laut, serta mengkarakterisasi komposit terbaik. 
Tabel 1. Komposisi Pembuatan Komposit

\begin{tabular}{ccccc}
\hline \multirow{2}{*}{ Sampel } & \multicolumn{2}{c}{ Komposisi } & \multicolumn{2}{c}{ Perekat } \\
\cline { 2 - 5 } & Filler & Matrix & Tepung Tapioka & Maleic Anhydride \\
\hline KPL 1 & 3 gram & 7 gram & 2,5 gram & 1,5 gram \\
KPL 2 & 4 gram & 6 gram & 2,5 gram & 1,5 gram \\
KPL 3 & 5 gram & 5 gram & 2,5 gram & 1,5 gram \\
\hline
\end{tabular}

Keterangan:

1. KPL $1=30 \%$ filler $: 70 \%$ matriks.

2. KPL $2=40 \%$ filler $: 60 \%$ matriks.

3. KPL $3=50 \%$ filler $: 50 \%$ matriks.

\section{Pembuatan Komposit}

\section{Pembuatan Serbuk Daun Pandan Laut}

Daun pandan laut dibersihkan dari durinya, selanjutnya dicuci dan ditiriskan, kemudian dipotong-potong sampai berukuran 1-2 cm, dikeringkan hingga kadar air kurang dari 10\%, dihancurkan menjadi serbuk dengan blender, kemudian dilakukan uji analisis kadar air dan densitas.

\section{Pembuatan Fraksi Selulosa}

Daun pandan laut direndam dalam $\mathrm{NaOCl} 1 \%$ selama 5 jam dengan suhu $28^{\circ} \mathrm{C}$, kemudian dicuci hingga bersih dan dilakukan pengeringan pada suhu $50^{\circ} \mathrm{C}$ selama $48 \mathrm{jam}$. Perendaman dilanjutkan dengan larutan $\mathrm{NaOH} 15 \%$ selama 24 jam pada suhu $28^{\circ} \mathrm{C}$, Serbuk daun pandan laut dikeringkan lagi pada suhu $50^{\circ} \mathrm{C}$ selama 48 jam. Setelah semua proses ini selesai maka didapatkan serbuk fraksi selulosa daun pandan laut yang siap digunakan untuk penelitian pembuatan komposit.

\section{Pembuatan matriks limbah plastik polyethylene terephthalate (PET)}

Pembuatan matriks dilakukan melalui beberapa tahapan yaitu: limbah plastik PET dicuci hingga bersih, dipotong-potong dan dikeringkan. Selanjutnya dipanaskan dengan menggunkan alat pirolisis selama \pm 2 jam 15 menit. Hasil dari proses pirolisis berbentuk seperti arang yang kemudian diblender dan disaring menggunakan saringan, dan selanjutnya dilakukan analisis densitas sampel plastik PET.

\section{Pencetakan komposit}

Pencetakan komposit dilakukan dengan penambahan matriks polyethylene terephthalate. Pencetakan komposit dilakukan melalui beberapa tahapan yaitu: pembuatan larutan perekat dengan kombinasi antara maleic anhydride sebanyak $15 \%$ + tepung tapioka sebanyak $25 \%$ yang telah dilarutkan dengan air sebanyak $10 \mathrm{ml}$, kemudian ditambahkan matriks polyethylene terephthalate dan di panaskan hingga suhu $170^{\circ} \mathrm{C}$. Setelah matriks dan perekat tercampur merata selanjutnya ditambahkan filler dari daun pandan laut dan dipanaskan hingga suhu $50^{\circ} \mathrm{C}$, dilakukan pencampuran dan pengadukan hingga merata, selanjutnya dilakukan pencetakan dalam casting dengan ukuran $4,5 \times 4,5 \times 1 \mathrm{~cm}$.

\section{Karakterisasi Komposit Terbaik \\ Uji Kadar Air}

Penentuan kadar air yaitu pertamatama cawan petri kosong dikeringkan dalam oven pada suhu $105^{\circ} \mathrm{C}$ selama 30 menit, cawan tersebut didinginkan didalam desikator selama \pm 15 menit dan kemudian cawan diambil dari desikator dan ditimbang dengan neraca analitik, cawan tersebut disi sampel komposit dan ditimbang beratnya, cawan yang telah disi sampel kemudian dimasukkan kedalam oven dengan suhu $105^{\circ} \mathrm{C}$ selama 2 jam, cawan tersebut kemudian didinginkan dalam desikator selama 15 menit, kemudian ditimbang dan dicatat hasilnya dan lakukan perhitungan kadar air. Menurut SNI SNI 03-2105-2006 tentang papan partikel bahwa penentuan 
kadar air dapat dihitung menggunakan persamaan sebagai berikut:

Keterangan:

$$
\% \text { Kadar Air }=\frac{\mathrm{A}-\mathrm{B}}{\mathrm{C}} \times 100 \%
$$

$$
\begin{aligned}
\mathrm{A} & =\text { Berat cawan kosong }+ \text { sampel (gram) } \\
\mathrm{B} & =\text { Berat cawan dengan sampel yang sudah } \\
\text { dikeringkan (gram) } & \\
\mathrm{C} & =\text { Berat Sampel (gram) }
\end{aligned}
$$

\section{Densitas}

Pengujian densitas komposit dilakukan dengan dua perlakuan yaitu pengujian densitas aktual dan teoritis. Prinsip pelaksanaan analisis densitas aktual yaitu dengan cara ditimbang berat sampel komposit, kemudian dimasukkan kedalam gelas beaker yang diisi air. Diukur dan dicatat kenaikan volume yang terjadi dan selanjutnya dilakukan perhitungan densitas aktual. Menurut SNI SNI 03-2105-2006 tentang papan partikel dan menurut Hairiyah, dkk (2017) bahwa penentuan nilai densitas suatu sampel dapat dihitung menggunakan persamaan sebagai berikut:

$$
\rho=\frac{\text { massa }}{\text { volume }}
$$

Prinsip pelaksanaan analisis densitas teoritis yaitu dengan cara ditimbang berat sampel komposit, kemudian dilakukan penentuan nilai volume komposit sesuai dengan penampakan visual yang terlihat dengan pengukuran sisi-sisi dari komposit tersebut yaitu dengan persamaan sebagai berikut:

$$
\text { Volume }=\text { Panjang } \mathrm{x} \text { Lebar } \mathrm{x} \text { Tinggi }
$$

\section{Porositas}

Porositas adalah perbandingan volume rongga-rongga pori terhadap volume total seluruh suatu bahan. Porositas suatu bahan pada umumnya dinyatakan sebagai porositas terbuka. Berdasarkan SNI SNI 03-2105-2006 tentang papan partikel dan menurut Sulardjaka, et al (2011) bahwa penentuan nilai porositas dapat dinyatakan dengan persamaan sebagai berikut:

$$
\text { Porositas }(\%)=1-\frac{\text { Densitas Aktual }}{\text { Densitas Teoritis }}
$$

\section{Daya Serap Air}

Pengujian daya serap air komposit yaitu dengan melakukan perendaman sampel komposit kedalam air. Komposit terlebih dahulu ditimbang untuk dicatat massa awalnya. Kemudian komposit direndam 8-16 jam, selanjutnya diambil dan dibersihkan dengan tisu sampai permukaan komposit benar-benar kering dan ditimbang sebagai berat setelah perendaman. Berdasarkan SNI SNI 032105-2006 tentang papan partikel dan menurut (Izaak, et al., 2013), pengujian daya serap air dapat ditentukan dengan persamaan sebagai berikut:

$$
\text { Daya Serap Air }=\frac{\text { Berat Setelah Setelah }- \text { Berat Sebelum Perendaman }}{\text { Berat Sebelum Perendaman }}
$$

\section{HASIL DAN PEMBAHASAN}

\section{Hasil Pembuatan Komposit}

Berdasarkan pembuatan komposit dari limbah plastik polyethylene terephthalate (PET) berbasis serat alam daun pandan laut (pandanus tectorius) pada masing-masing perlakuan dengan penambahan kombinasi perekat antara maleic anhydride (MAH) dan tepung tapioka sehingga didapatkan hasil sebagai berikut. 
Tabel 2. Hasil Pembuatan Komposit

\begin{tabular}{|c|c|c|c|c|c|}
\hline \multirow[b]{2}{*}{ Sampel } & \multicolumn{2}{|c|}{ Bahan Perekat } & \multirow[b]{2}{*}{ Hasil } & \multirow{2}{*}{$\begin{array}{l}\text { Ukuran Komposit } \\
(\mathrm{Cm})\end{array}$} & \multirow[b]{2}{*}{ Keterangan } \\
\hline & $\begin{array}{c}\text { MAH } \\
(\%)\end{array}$ & $\begin{array}{c}\text { Tapioka( } \\
\%)\end{array}$ & & & \\
\hline \multirow[b]{2}{*}{ KPL 1} & \multirow[b]{2}{*}{15} & \multirow[b]{2}{*}{25} & & \multirow[b]{2}{*}{$4,5 \times 4,5 \times 1$} & $\begin{array}{c}\text { Matriks dan filler tercampur } \\
\text { secara merata dan bertekstur } \\
\text { padat dan keras }\end{array}$ \\
\hline & & & & & \\
\hline \multirow{3}{*}{ KPL 2} & \multirow{3}{*}{15} & \multirow{3}{*}{25} & & \multirow{3}{*}{$4,5 \times 4,5 \times 1$} & $\begin{array}{c}\text { Matriks dan filler tercampur } \\
\text { secara merata dan bertekstur } \\
\text { padat dan keras }\end{array}$ \\
\hline & & & & & \\
\hline & & & 40.60 & & \\
\hline \multirow{3}{*}{ KPL 3} & \multirow{3}{*}{15} & \multirow{3}{*}{25} & & \multirow{3}{*}{$4,5 \times 4,5 \times 1$} & $\begin{array}{c}\text { Matriks dan filler tercampur } \\
\text { secara merata dan bertekstur } \\
\text { padat dan lebih keras }\end{array}$ \\
\hline & & & & & \\
\hline & & & $80: 50$ & & \\
\hline
\end{tabular}

\section{Karakterisasi Komposit Terbaik Kadar Air} Kadar air merupakan sejumlah air yang terkandung di dalam suatu produk atau bahan. Hasil pengujian kadar air komposit yang telah dilakukan dapat dilihat pada Gambar 1 sebagai berikut:

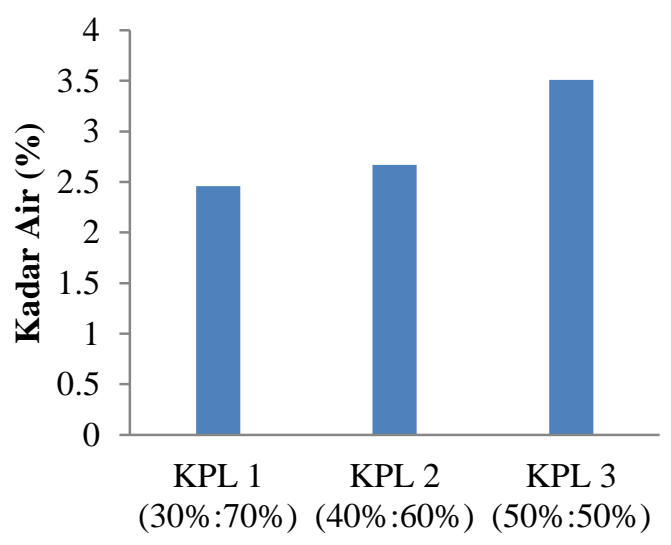

\section{Jenis Komposit}

Gambar 1. Penambahan rasio filler dan matriks terhadap kadar air komposit
Berdasarkan hasil pengujian kadar air jenis komposit yang dilakukan dapat diketahui bahwa kadar air komposit jenis KPL 1, KPL 2, dan KPL 3 sudah memenuhi standar mutu menurut SNI 014449-2006 yaitu memiliki kadar air tidak lebih dari 13\% (Badan Standardisasi Nasional, 2006). Tingginya kadar air suatu jenis komposit salah satunya dipengaruhi oleh serat dan plastik PET yang terkandung didalamnya, semakin banyak kandungan serat pada jenis komposit tersebut maka semakin tinggi kadar air yang terkandung didalamnya. Hal ini karena bahan alam atau serat alam pada komposit yang memilki kemampuan dalam menyerap kandungan air. Serat memiliki kadar air sehingga apabila komposisi serat yang digunakan dalam pembuatan komposit semakin banyak maka kadar air komposit yang dihasilkan akan semakin bertambah juga (Gulo, et al., 2013).

Berbanding terbalik dengan banyaknya serat, semakin banyak kandungan plastik PET pada komposit 
berakibat penurunan nilai kadar air pada jenis komposit tersebut. Semakin banyak komposisi plastik yang digunakan, maka kadar air papan komposit yang dihasilkan semakin kecil dan semakin sedikit plastik yang digunakan maka kadar air papan komposit yang dihasilkan semakin tinggi (Rita, et al., 2015). Penurunan kadar air erat kaitannya dengan sifat dari partikel plastik itu sendiri yang kedap air, artinya partikel plastik tidak mempunyai kemampuan untuk menyerap air dari lingkungan sekitarnya (Sari, 2011).

\section{Densitas}

Massa jenis (densitas) adalah pengukuran massa setiap satuan volume benda. Hasil pengujian densitas komposit yang telah dilakukan dapat dilihat pada Gambar 2 sebagai berikut:

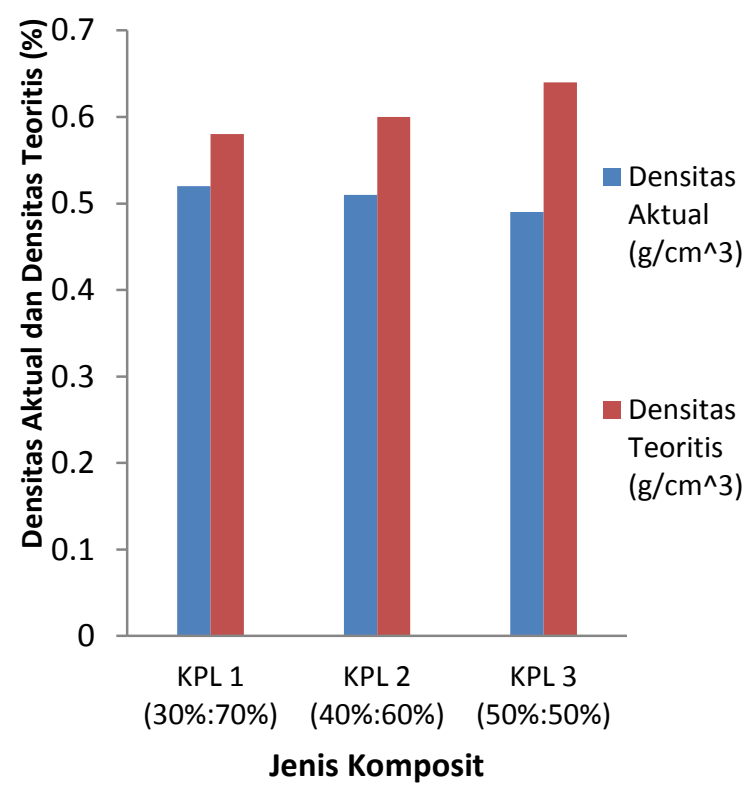

Gambar 2. Hasil Pengujian Densitas Komposit

Berdasarkan pengujian densitas yang telah dilakukan dapat diketahui nilai densitas teoritis komposit jenis KPL 1 yaitu $0,58 \mathrm{~g} / \mathrm{cm}^{3}$, jenis KPL 2 yaitu $0,60 \mathrm{~g} / \mathrm{cm}^{3}$, dan jenis KPL 3 yaitu $0,64 \mathrm{~g} / \mathrm{cm}^{3}$. Hal tersebut karena pada penentuan densitas teoritis berdasarkan pengukuran volume fisik komposit yang terlihat secara visual, selain itu tingginya nilai densitas teoritis dipengaruhi oleh banyaknya serat yang terkandung pada jenis komposit tersebut. Semakin banyak serat maka akan mempengaruhi bentuk fisik komposit yang semakin besar, hal ini karena densitas daun pandan yang lebih ringan dibanding densitas plastik PET sehingga akan menghasilkan volume fisik komposit yang terlihat secara visual semakin besar dan akan berpengaruh terhadap besarnya nilai densitas teoritis yang dihasilkan.

Penentuan nilai densitas aktual yang dilakukan dapat diketahui nilai densitas aktual komposit jenis KPL 1 yaitu 0,52 $\mathrm{g} / \mathrm{cm}^{3}$, jenis KPL 2 yaitu $0,51 \mathrm{~g} / \mathrm{cm}^{3}$, dan jenis KPL 3 yaitu $0,49 \mathrm{~g} / \mathrm{cm}^{3}$. Densitas dari jenis komposit (KPL 1, KPL 2, dan KPL 3) sudah memenuhi standar mutu densitas komposit, hal ini karena menurut SNI 032105-2006 bahwa ketiga jenis komposit tersebut memiliki nilai kerapatan ayang sesuai standar yaitu antara $0,40 \mathrm{~g} / \mathrm{cm}^{3}-0,90$ $\mathrm{g} / \mathrm{cm}^{3}$ (Badan Standardisasi Nasional, 2006).

Berdasarkan nilai densitas yang diperoleh maka dapat diketahui jenis komposit (KPL 1, KPL 2, dan KPL 3) termasuk sebagai jenis komposit dengan klasifikasi papan serat kerapatan sedang. Menurut SNI 01-4449-2006 bahwa komposit dapat diklasifikasikan berdasarkan kerapatannya yaitu papan serat kerapatan rendah (PSKR) yaitu papan serat yang memiliki kerapatan $<0,40 \mathrm{~g} / \mathrm{cm}^{3}$, papan serat kerapatan sedang (PSKS) yaitu papan serat yang memiliki kerapatan 0,40$0,84 \mathrm{~g} / \mathrm{cm}^{3}$, dan papan serat kerapatan tinggi (PSKT) yaitu papan serat yang memiliki kerapatan $>0,84 \mathrm{~g} / \mathrm{cm}^{3}$ (Badan Standardisasi Nasional, 2006). Besarnya nilai densitas aktual berbanding terbalik dengan nilai densitas teoritis, hal tersebut karena pada pengujian densitas aktual rongga-rongga yag terdapat pada sampel terisi oleh air secara sempurna sehingga menghasilkan nilai densitas yang lebih tepat. Besarnya nilai densitas aktual juga salah satunya dipengaruhi oleh bahan penyusun komposit tersebut yaitu plastik PET dan serat selulosa daun pandan laut. Berdasarkan pengujian yang dilakukan 
diketahui bahwa plastik PET memiliki densitas yang lebih besar dibandingkan densitas daun pandan laut yaitu sebesar $0,67 \mathrm{~g} / \mathrm{cm}^{3}$ dan daun pandan laut yaitu sebesar $0,5 \mathrm{~g} / \mathrm{cm}^{3}$, sehingga semakin besar kandungan plastik PET akan menghasilkan nilai densitas aktual yang semakin besar pula.

\section{Porositas}

Porositas adalah perbandingan volume rongga-rongga pori terhadap volume total seluruh suatu bahan. Hasil pengujian porositas komposit yang telah dilakukan dapat dilihat pada Gambar 3 sebagai berikut:

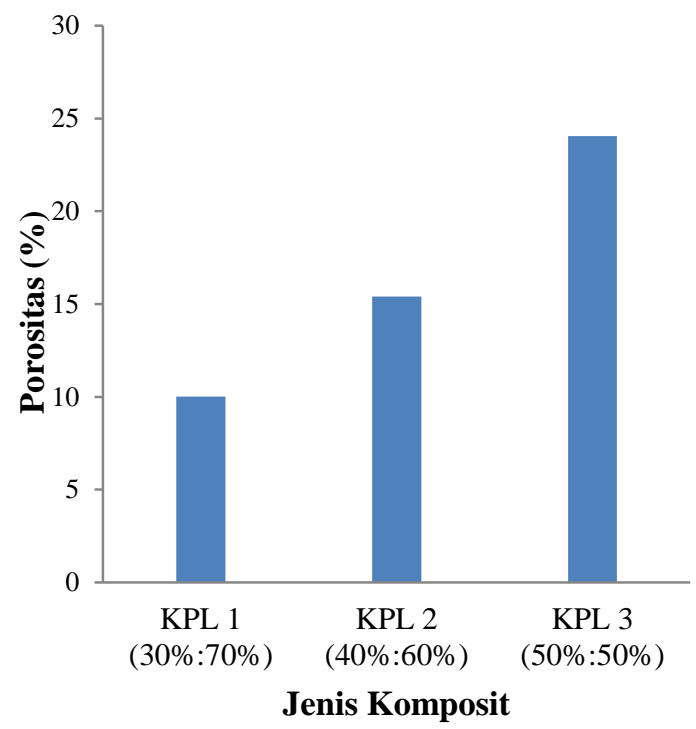

Gambar 3. Hasil Pengujian Porositas Komposit

Berdasarkan penentuan nilai porositas jenis komposit (KPL 1, KPL 2, dan KPL 3) yang dilakukan dapat diketahui nilai porositas yang diperoleh pada jenis komposit (KPL 1, KPL 2, dan KPL 3) telah memenuhi standar mutu dari SNI 03-21052006 yaitu memiliki nilai porositas $<25 \%$ (Badan Standardisasi Nasional, 2006). Besarnya nilai porositas yang diperoleh jenis komposit secara umum dipengaruhi oleh massa jenis (densitas) dari komposit tersebut. Hal ini karena densitas berkaitan erat dengan kerapatan massa penyusun dari jenis komposit tersebut. Nilai densitas bahan komposit ini saling berhubungan dengan nilai porositas. Nilai porositas suatu bahan berbanding terbalik dengan densitas bahan komposit tersebut, hal ini karena porositas adalah rongga yang terdapat pada bahan komposit dan akan mempengaruhi densitas bahan tersebut. Semakin padat suatu bahan maka densitasnya akan semakin tinggi dan porositas akan semakin kecil, begitu juga sebaliknya. Porositas pada bahan komposit dapat menurunkan sifat bahan seperti kekerasan dan laju keausan, yang pada akhirnya mempengaruhi sifat karakteristik bahan (Sunardi, et al., 2015).

\section{Uji Daya Serap Air}

Daya serap air merupakan sifat fisis papan komposit yang menunjukkan sifat kemampuan papan untuk menyerap air selama perendaman di dalam air. Hasil pengujian daya serap air komposit yang telah dilakukan dapat dilihat pada Gambar 4 sebagai berikut:



Jenis Komposit

Gambar 4. Hasil Pengujian Daya Serap Air Komposit

Berdasarkan penentuan nilai daya serap air yang dilakukan dapat diketahui daya serap air komposit jenis KPL 1 yaitu $24,88 \%$, jenis KPL 2 yaitu 37,44\%, dan jenis KPL 3 yaitu 46,51\%. Menurut standar JIS A5905-2003, daya serap air komposit papan serat yaitu maksimum $25 \%$ 
(Manurung, et al., 2013). Berdasarkan nilai daya serap air yang diperoleh, maka dapat diketahui hanya jenis komposit KPL 1 yang memenuhi standar daya serap air komposit. Besarnya nilai daya serap air pada jenis komposit tersebut dipengaruhi oleh nilai densitas dan porositas jenis komposit. Hal ini karena densitas menjadi parameter kerapatan massa suatu jenis komposit dan porositas menjadi parameter banyaknya rongga pada jenis komposit tersebut. Semakin tinggi nilai densitas dan rendahnya nilai porositas maka akan semakin rendah daya serap air yang dimiliki oleh komposit tersebut. Begitu juga sebaliknya, semakin rendah nilai densitas dan semakin tinggi nilai porositas maka akan semakin tinggi kemampuan daya serap air suatu jenis komposit.

Kerapatan sangat bergantung pada kerapatan bahan yang akan digunakan serta tekanan yang diberikan selama proses pengempaan. Semakin tinggi kerapatan komposit yang akan dibuat akan semakin besar tekanan yang digunakan pada saat pengempaan (Haygreen dan Bowyer 1989). Semakin tinggi kerapatan komposit, semakin banyak bahan yang dibutuhkan untuk membuat komposit pada ukuran yang sama.

Faktor yang mempengaruhi komposit terhadap penyerapan air adalah volume rongga kosong yang dapat menampung air diantara partikel, adannya saluran kapiler yang menghubungkan ruang kosong, permukaan komposit yang tidak tertutupi perekat dan dalamnya penetrasi perekat terhadap partikel (Sari, 2012). Komposit sangat mudah menyerap air pada arah tebal terutama dalam keadaan basah dan suhu udara lembab.

Hal tersebut selaras dengan penelitian yang dilakukan oleh Fathanah (2011), bahwa semakin tinggi kerapatan papan komposit, maka ikatan antar partikel akan semakin kompak sehingga rongga udara dalam lembaran papan semakin kecil, dan keadaan tersebut akan menyebabkan air atau uap air menjadi sulit untuk mengisi rongga tersebut sehingga semakin kecil daya serap air papan komposit sehingga stabilitas papan tersebut semakin baik, demikian pula sebaliknya. Daya serap air dipengaruhi oleh banyaknya rongga-rongga udara yang terdapat pada jenis komposit, hal tersebut karena pada struktur permukaan serat masih terlihat ronggarongga yang masih terbuka yang memudahkan terjadinya penyerapan air (Matheus, et al., 2013).

\section{KESIMPULAN}

Pembuatan komposit dapat dilakukan dengan pembuatan serbuk daun pandan laut, pembuatan fraksi selulosa, pembuatan matriks dari limbah plastik polyethylene terephthalate, dan pencetakkan komposit pada casting dengan penambahan perekat (maleic anhydride 15\% dan tepung tapioka 25\%). Karakterisasi komposit yang diperoleh yaitu jenis komposit KPL 1, KPL 2, dan KPL 3 memiliki nilai kadar air dan densitas yang telah sesuai dengan SNI 014449-2006, jenis komposit KPL 1, KPL 2, dan KPL 3 memiliki nilai porositas yang telah sesuai SNI 03-2105-2006, serta hanya jenis KPL 1 yang memiliki daya serap air yang sesuai dengan standar JIS A59052003. Berdasarkan karakerisasi yang dilakukan maka diketahui jenis komposit KPL 1 memiliki karakteristik terbaik untuk dilakukan pengembangan lebih lanjut karena memiliki nilai kadar air, densitas, porositas, dan daya serap air yang sesuai dengan standar yang berlaku.

\section{UCAPAN TERIMA KASIH}

Terima kasih kepada Politeknik Negeri Tanah Laut yang telah memberikan dana Penelitian Dosen Dana DIPA (PD3) Tahun 2020 dengan nomor kontrak 016/PL40.5/LT/2020. 


\section{DAFTAR PUSTAKA}

Armidion, R. dan Rahayu, T., 2018. Peningkatan Nilai Kuat Tarik Belah Beton dengan Campuran Limbah Botol Plastik Polyetylene Terephthalate (PET). Jurnal Konstruksia, 10(1): 117-126.

BSN, 2006. SNI 01-4449-2006 tentang Standard Nasional Papan Serat. Jakarta: Badan Standardisasi Nasional.

BSN, 2006. SNI 03-2105-2006 tentang Standard Nasional Papan Partikel. Jakarta: Badan Standardisasi Nasional.

Dewi, I. P. dan Sofia, L. A., 2020. Pengembangan Bisnis Pembibitan Mangrove untuk Abrasi Pantai Di Desa Pagatan Besar, Kalimantan Selatan. PRO SEJAHTERA (Prosiding Seminar Nasional Pengabdian kepada Masyarakat), 2(1): 74-81.

Fathanah, U., 2011. Kualitas Papan Komposit dari Sekam Padi dan Plastik HDPE Daur Ulang Menggunakan Maleic Anhydride (MAH) sebagai Compatibilizer. Jurnal Rekayasa Kimia dan Lingkungan , 8(2): 53-59.

Gulo, W. Y., Sinuhaji, P. dan Syukur, M., 2013. Pembuatan dan Karakterisasi Komposit Serat Palem Saray dengan Matriks Epoksi. Jurnal Saintia Fisika, 3(1) : 1-5. https://media.neliti.com/media/public ations/221330-pembuatan-dankarakterisasi-komposit-ser.pdf.

Gusmailina, 2010. Peningkatan Teknik Pengolahan Pandan (Bagian 1) : Pewarnaan dan Pengeringan. Jurnal Penelitian Hasil Hutan, 28(1): 66-76.
Hairiyah, N., Amalia, R. dan Widyastuti, A., 2017. Pembuatan Mikrokomposit Purun Tikus (Eleocharis Dulcis) dan Eceng Gondok (Eichornia Crassipes) Sebagai Filler dengan Limbah Plastik Polyethylene Terephthalate (PET) Sebagai Matrix. Jurnal Teknologi Agro-Industri, 4(2): 61-72.

Hairiyah, N., Nuryati dan Meldayanoor, 2017. Karakteristik Mekanik Mikrokomposit Dari Tongkol Jagung Dan Limbah Plastik Polipropilene. Jurnal Teknologi Agro-Industri, 4(1): 1-10.

Izaak, F. D., Rauf, A. F. dan Lumintang, R., 2013. Analisis Sifat Mekanik dan Daya Serap Air Material Komposit Serat Rotan. Jurnal Online Poros Teknik Mesin, 2(2). https://ejournal.unsrat.ac.id/index.php /poros/article/view/2988/2533, 1-12.

Manurung, S. X., Sinuhaji, P. dan Syukur, M., 2013. Pembuatan dan Karakterisasi Komposit Serat Palem Saray dengan Matriks Poliester. Jurnal Saintia Fisika, 4(1).

Matheus, J., Irawan, Y. S. dan Soenoko, R., 2013. Pengaruh Perlakuan Silane dan $\mathrm{NaOH}$ pada Permukaan Serat Kontinyu Limbah Epulur Sagu (Metroxylon Sp) Terhadap Daya Serap Air dan Kekuatan Bending. Jurnal Rekayasa Mesin, 4(2): 212219.

Nopriantina, N. dan Astuti, 2013. Pengaruh Ketebalan Serat Pelepah Pisang Kepok (Musa Paradisiaca) Terhadap Sifat Mekanik Material Komposit Poliester-Serat Alam. Jurnal Fisika Unand, 2(3): 195-203.

Okatama, I., 2016. Analisa Peleburan Limbah Plastik Jenis Polyethylene Terphtalate (PET) Menjadi Biji Plastik Melalui Pengujian Alat 
Pelebur Plastik. Jurnal Teknik Mesin, 5(3): 20-24.

Rita, R., Setyawati, D. dan Usman, F. H., 2015. Sifat Fisik dan Mekanik Papan Komposit dari Batang Singkong dan Limbah Plastik Berdasarkan Pelapisan dan Komposisi Bahan Baku. Jurnal Hutan Lestari, 2(3): 337-346.

Saputra, A., Wicaksono, M. dan Irsan, 2017. Pemanfaatan Minyak Goreng Bekas untuk Pembuatan Biodiesel Menggunakan Katalis Zeolit Alat Teraktivasi. Jurnal Chemurgy, 1(2): 1-6.

Sari, N. M., 2011. Sifat Fisik dan Mekanik Papan Partikel dari Limbah Plastik Jenis Hdpe (High Density Polyetylene) dan Ranting/Cabang Karet (Hevea Brasiliensis Muell.Arg). Jurnal Riset Industri Hasil Hutan, 3(1): 7-14.

Sriwita, A., 2014. Pembuatan dan Karakterisasi Sifat Mekanik Bahan Komposit Serat Daun NenasPolyester Ditinjau dari Fraksi Massa dan Orientasi Serat. Jurnal Fisika Unand, 3(1): 30-36.

Sulardjaka, Wibowo, D., Arijanto dan Setiaji , E., 2011. Pengaruh
Temperatur Tuang pada Proses Pengecoran Stir Casting Terhadap Densitas dan Porositas Komposit Alumunium Diperkuat Serbuk Besi. Jurnal Teknik Mesin, 13(3): 19-21.

Sunardi, Fawaid, M. dan Noor, F. R., 2015. Variasi Campuran Fly Ash Batubara untuk Material Komposit. Jurnal Teknik Mesin UNTIRTA, 1(1): 90102.

Taufik, C. dan Astuti, 2014. Sintesis dan Karakterisasi Sifat Mekanik Serta Struktur Mikro Komposit Resin yang Diperkuat Serat Daun Pandan Alas (Pandanus Dubius). Jurnal Fisika Unand, 3(1): 41-47.

Widiartha, I., Sari, N. dan Sujita, 2012. Study Kekuatan Bending dan Struktur Mikro Komposit Polyethylene yang Diperkuat Oleh Hybrid Serat Sisal dan Karung Goni. Jurnal Dinamika Teknik Mesin, 2(2): 92-99.

Zulkifli, Hermansyah, H. dan Mulyanto, S., 2018. Analisa Kekuatan Tarik dan Bentuk Patahan Komposit Serat Sabuk Kelapa Bermatriks Epoxy terhadap Variasi Fraksi Volume Serat. Jurnal Teknologi Terpadu, 6(2): 90-95. 